\title{
Induction of proliferation in resting B-cells by a factor released by activated mouse spleen cells
}

\author{
Niti Puri ${ }^{1}$ and R. K. Saxena ${ }^{1,2}$ \\ 1 School of Life Sciences Jawaharlal Nehru University, New Delhi-110067, India \\ 2 Corresponding author: Fax, 91-11-6187338, 91-11-6165886; \\ E-mail, rksaxena@jnuniv.ernet.in \\ Accepted 4 September 1998
}

Abbreviations: PIF, proliferation inducing factor; MLR, mixed lymphocyte reaction; MHCAF, MHC I augmenting factor; LPS, lipopolysaccharide

\begin{abstract}
Mouse spleen cells activated in a mixed lymphocyte reaction release a soluble factor, which induces a significant proliferative response in fresh mouse spleen cells. This proliferation inducing factor (PIF) was found to be heat stable $\left(90^{\circ} \mathrm{C}\right.$ for $45 \mathrm{~min}$ ) and also resistant to trypsin or chymotrypsin treatment. By using a sizing HPLC column, the molecular weight of PIF appears to be $25 \mathrm{kDa}$. Mouse spleen cells treated with anti-thy-1 + complement lost Con-A induced proliferative responses but responded well to PIF. B cell depleted spleen cells obtained by negative selection panning, did not respond to PIF. These results indicate that $B$ cells proliferated in response to PIF. Polymixin-B, which blocks the B cell proliferative response to LPS, did not inhibit PIF induced proliferation.
\end{abstract}

Keywords: B cells, proliferation, cytokines, LPS, growth factor

\section{Introduction}

Activation, proliferation and differentiation of B lymphocytes are all controlled by signals delivered through receptors on the cell surface. These signals include antigen, interaction with molecules on the surface of other cell types, and a host of growth and differentiation inducing cytokines. Many of these cytokines are derived from $T$ cells and are involved in T cell-B cell collaboration, but some are made by B cells, monocytes and a variety of non-lymphoid cells.

We had previously identified a factor, distinct from interferon, which augments the expression of $\mathrm{MHC}$ class I molecules on tumor cells (Saxena et al., 1993, 1996;
Puri and Saxena, 1998). Partially purified preparations of this MHC I augmenting factor (MHC-AF) were found to induce proliferation in fresh mouse spleen cells. In the present paper, we have attempted to characterize this proliferation inducing factor (PIF). This novel PIF released by activated mouse spleen cells appears to be distinct from MHC-AF as cell fractionation studies indicate that it induces proliferation in resting $B$ cells.

\section{Materials and Methods}

\section{Animals}

Inbred C57BI/6, BALB/c and outbred Swiss albino mice (8-12 weeks) were used throughout this study. New Zealand white rabbits were used as a source of complement. All animals were bred and maintained in the Animal House Facility in Jawaharlal Nehru University, New Delhi.

\section{Spleen cell fractionation}

The procedure for depletion of adherent cells and B cells by passage through nylon wool columns and T cells by anti thy- 1 and complement treatment, have been described before (Julius et al., 1973; Saxena and Adler, 1979). Complete depletion of B cells by panning was done as follows. Plastic sterile petri dishes $(5 \mathrm{~cm}$ diameter, from Costar) were coated overnight with 100 $\mu \mathrm{g}$ of affinity purified rabbit anti-mouse $\mathrm{Ig}$ in a volume of $3-4 \mathrm{ml}$ at $4^{\circ} \mathrm{C}$. The plates were washed with PBS and blocked with $4 \mathrm{ml}$ of RPMI-1640 containing $2 \%$ FCS for $30 \mathrm{~min}$. Mouse spleen cells $\left(25 \times 10^{6}\right)$ in a volume of 3 $\mathrm{ml}$ were added to each petri dish and these were incubated at room temperature for $30 \mathrm{~min}$. Plates were swirled and left undisturbed for an additional $30 \mathrm{~min}$. Unbound cells were harvested by a pipette. These cell preparations had less than $1 \%$ Ig-positive cells by fluorescence microscopy.

\section{Proliferation Assay}

Normal spleen cells $\left(2 \times 10^{5}\right.$ in $0.2 \mathrm{ml}$ of complete medium per assay well ) were cultured with or without test agents in 96-well plates. At the desired time, cells were pulsed with $0.5 \mu \mathrm{Ci}\left[{ }^{3} \mathrm{H}\right]$ thymidine (methyl-T thymidine, specific activity $18,000 \mathrm{mCi} / \mathrm{mmole}$, from BRIT Bombay) per well from 6 to $18 \mathrm{~h}$. Cells were harvested by an automated cell harvester (PHD cell harvester, Cambridge Technology) onto glass fibre discs and deposited in scintillation vials. After drying the discs, $1 \mathrm{ml}$ scintillation cocktail was added per vial which were kept overnight in the dark. The incorporated $\left[{ }^{3} \mathrm{H}\right]$ thymidine was determined as counts 
per well by using a Beckmann or LKB beta scintillation counter.

\section{Preparation of mouse PIF}

For the PIF preparation from mixed lymphocyte culture supernatants, spleen cells $\left(5 \times 10^{6} \mathrm{cells} / \mathrm{ml}\right)$ from BALB/c or $\mathrm{C} 57 \mathrm{BI} / 6$ mice were cultured with spleen cells from Swiss mice at a ratio of 1:5, in RPMI-1640 medium containing $2 \%$ FCS, or in DCCM-2 serum free medium (Biological Industries, Israel). After 5 days culture, supernatants were harvested by pelleting the cells the proteins in the supernatant, precipitated by adding ammonium sulfate ( $85 \%$ saturation, overnight at $4^{\circ} \mathrm{C}$ ). Protein precipitate was pelleted by centrifugation at 10,000 rpm for $15 \mathrm{~min}$, resuspended in deionized water, and dialyzed against two changes of $0.1 \mathrm{M}$ Glycine- $\mathrm{HCl}$ buffer $\mathrm{pH} 2.0$ (total $48 \mathrm{~h}$ ), followed by two changes of PBS. Any insoluble material present at this stage was removed by centrifugation and the solution was concentrated on an Amicon $3 \mathrm{~K}$ membrane filter to about $30 \mathrm{ml}$ for each liter of culture supernatant processed.

\section{Sephadex G-100 column chromatography}

Ten $\mathrm{ml}$ of the crude concentrate obtained by processing the culture supernatants was fractionated on a Sephadex G-100 column $(25 \times 600 \mathrm{~mm})$. The column was run at $4^{\circ} \mathrm{C}$ at a flow rate of $35 \mathrm{ml} / \mathrm{h}$ in PBS and $10 \mathrm{ml}$ fractions collected. Fractions with PIF activity were pooled and concentrated using Amicon $3 \mathrm{~K}$ membrane filters.

\section{Results}

\section{Induction of proliferation of spleen cells by PIF}

We have previously identified a soluble factor released by mouse spleen cells activated in a mixed lymphocyte reaction (MLR), which could augment the expression of class I MHC antigens on tumor cell lines. Preparations of this factor MHC-AF were found to induce a significant proliferative response in fresh unimmunized mouse spleen cells. We tentatively named this activity as proliferation inducing factor (PIF) and attempted to characterize it further. Crude preparations obtained after ammonium sulfate precipitation and dialysis against a buffer ( $\mathrm{pH} 2.0$ ), of supernatants of mouse spleen cells undergoing an MLR, were fractionated on a Sephadex G100 column and PIF activity was tested. Eluted PIF activity was shown as a broad peak from the Sephadex G-100 column (Figure 1A). Fractionation of identically processed culture medium (RPMI-1640 medium with $2 \%$ FCS), through the G-100 column did not yield any fractions with PIF activity (Figure 1B). Figure $2 \mathrm{~A}$ shows a dose dependent increase in the proliferative activity of spleen cells from different strains of mice, in response to the PIF. Time kinetics on the effect of PIF on mouse spleen cells indicates that the maximum effect was obtained on day 2 of culture (Figure 2B). Cells derived from other lymphoid organs were also used to study the proliferative response to PIF (Figure 3). PIF induced proliferative activity in spleen cells, but no signi-ficant effect was noted on thymus and bone marrow cells.

\section{Heat stability of PIF}

To study the properties of PIF, aliquots of PIF preparation were kept at $37^{\circ} \mathrm{C}, 56^{\circ} \mathrm{C}, 72^{\circ} \mathrm{C}$ and $90^{\circ} \mathrm{C}$ for $45 \mathrm{~min}$ each and then tested for their effects on mouse spleen cells. Results in Table 1 show that heating up to $90^{\circ} \mathrm{C}$ for $45 \mathrm{~min}$ did not abrogate the PIF activity, indicating

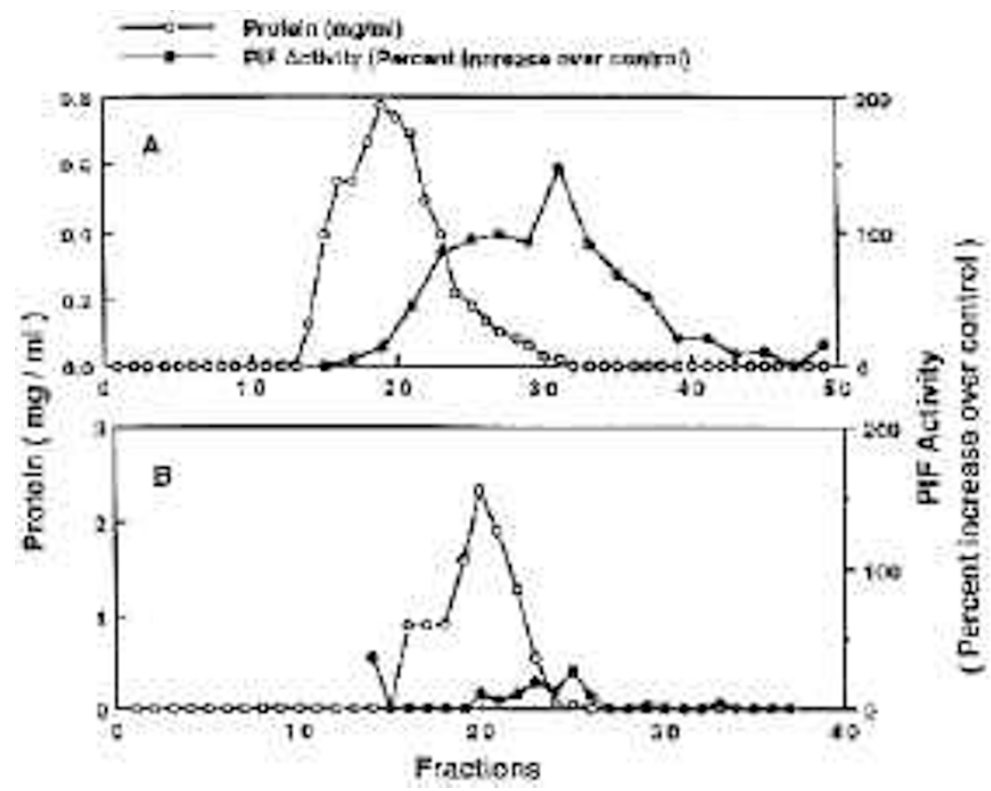

Figure 1. The elution profile of PIF on a Sephadex G-100 column. A crude MLC supernatant preparation obtained after ammonium sulfate precipitation and dialysis against a buffer $(\mathrm{pH}$ 2.0), of culture supernatant from C57BI/6 Vs Swiss MLR, generated in RPMI-1640 and containing 2\% FCS (A) was loaded on a Sephadex G-100 column ( 25 X $600 \mathrm{~mm}$ ). The protein content of each fraction was determined by Bradfords method. The PIF activity of fractions was assayed by a $\left[{ }^{3} \mathrm{H}\right]$ thymidine incorporation assay of mouse spleen cells as described in 'Materials and Methods'. As a control PIF activity in Sephadex G-100 fractions of a similarly processed RPMI-1640 (2\% FCS) medium, was also studied (B). Each point represents a mean + $\mathrm{SD}$ value obtained from three replicate assay wells. 
Table 1. Effect of heat treatment on the biological activity of PIF. Mouse spleen cells were cultured with either a control or heat treated PIF preparation $(20 \% \mathrm{v} / \mathrm{v})$. After $30 \mathrm{~h}$ the cells were pulsed with $\left[{ }^{3} \mathrm{H}\right]$ thymidine and the CPM determined, as described in 'Materials and Methods'. Each value is a mean \pm SEM of three observations.

\begin{tabular}{lccr}
\hline $\begin{array}{l}\text { Treatment of } \\
\text { spleen cells }\end{array}$ & Exp.1 & CPM (mean \pm SEM) & Exp.2 \\
\hline Untreated & $1,367 \pm 174$ & $2,455 \pm 166$ & $3,182 \pm 297$ \\
PIF & & $21,643 \pm 910$ & $20,539 \pm 841$ \\
$16443 \pm 225$ & & & \\
$37^{\circ} \mathrm{C}$ treated PIF & $20,175 \pm 155$ & $19,962 \pm 101$ & $18,454 \pm 61$ \\
$56^{\circ} \mathrm{C}$ treated PIF & $20,364 \pm 302$ & $19,840 \pm 244$ & $15,798 \pm 104$ \\
$72^{\circ} \mathrm{C}$ treated PIF & $19,054 \pm 440$ & $20,909 \pm 839$ & $13,761 \pm 229$ \\
$90^{\circ} \mathrm{C}$ treated PIF & $22,407 \pm 549$ & $17,512 \pm 656$ & $14,933 \pm 103$ \\
\hline
\end{tabular}
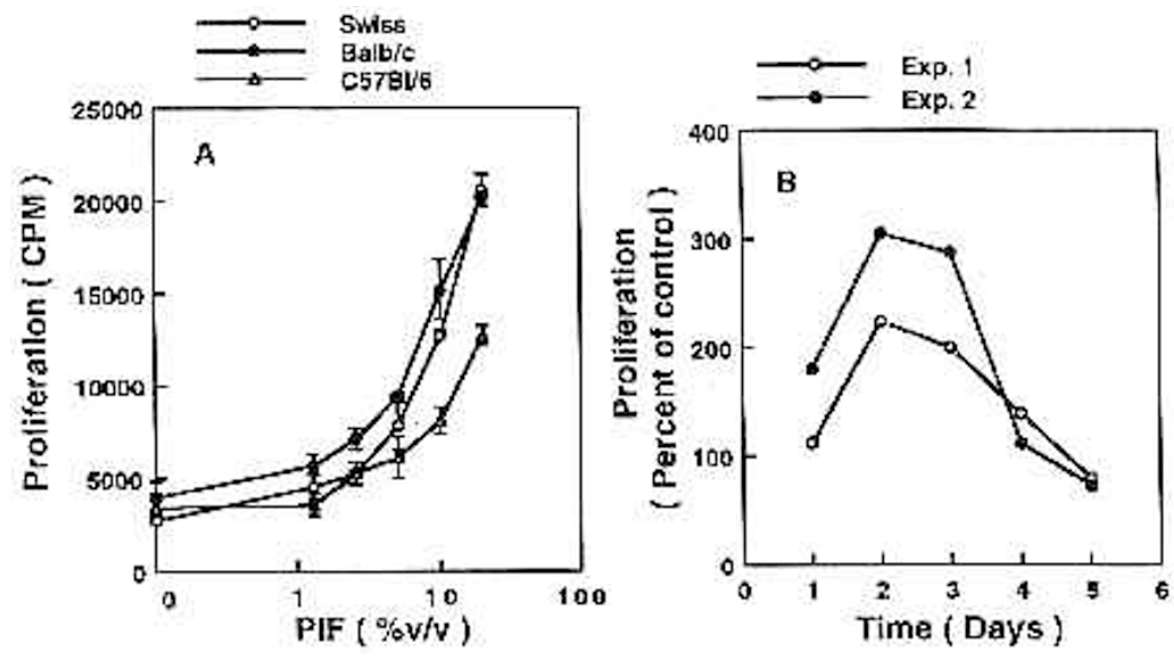

Figure 2. A. Dose response of the proliferation of mouse spleen cells in the presence of PIF. Spleen cells from different strains of mice, namely; Swiss albino, Balb/c and C57BI/6 were cultured, with different concentrations of PIF. After $30 \mathrm{~h}$ of culture, an $18 \mathrm{~h}$ pulse of $\left[{ }^{3} \mathrm{H}\right]$ thymidine was given and an incorporated c.p.m. determined. B. Time of proliferation of mouse spleen cells in response to PIF. Mouse spleen cells were cultured with and without $10 \%$ PIF and harvested on different days after an 18 h pulse of $\left[{ }^{3} \mathrm{H}\right]$ thymidine and the c.p.m. determined. Plotted here is the c.p.m. obtained in the presence of PIF as a percentage of the control. Results from two representative experiments are shown. Each point on the curve represents a mean \pm SD of three replicate assay wells. Variations were less than $5 \%$ of mean value.
Table 2. Effect of trypsin or chymotrypsin beads on the biological activity of PIF. PIF preparations were incubated with or without trypsin or chymotrypsin coated sepharose $\mathrm{CL}-48$ beads at $37^{\circ} \mathrm{C}$ for two hours. After the incubation, the beads were removed from the PIF preparations by centrifugation. Proliferation of mouse spleen cells in response to control and enzyme treated PIF preparations was examined by the incorporation of the $\left.{ }^{3} \mathrm{H}\right]$ thymidine as described in 'Materials and Methods'.

\begin{tabular}{lcc}
\hline $\begin{array}{l}\text { Treatment of } \\
\text { spleen cells }\end{array}$ & \multicolumn{2}{c}{ CPM (mean \pm SEM) } \\
Exp.1 & Exp. 2 \\
\hline $\begin{array}{l}\text { Untreated } \\
20 \% \text { v/v PIF }\end{array}$ & $1,581 \pm 23$ & $1,196 \pm 92$ \\
$\begin{array}{l}\text { Trypsin beads } \\
\text { treated with PBS }\end{array}$ & $1,032 \pm 490$ & $7,167 \pm 615$ \\
$\begin{array}{l}\text { Trypsin beads } \\
\text { treated with PIF }\end{array}$ & $18,083 \pm 2384$ & $1,621 \pm 90$ \\
$\begin{array}{l}\text { Chymotrypsin beads } \\
\text { treated with PBS }\end{array}$ & $2,736 \pm 386$ & $1,925 \pm 81$ \\
$\begin{array}{l}\text { Chymotrypsin beads } \\
\text { treated with PIF }\end{array}$ & $16,307 \pm 1627$ & $17,809 \pm 497$ \\
\hline
\end{tabular}

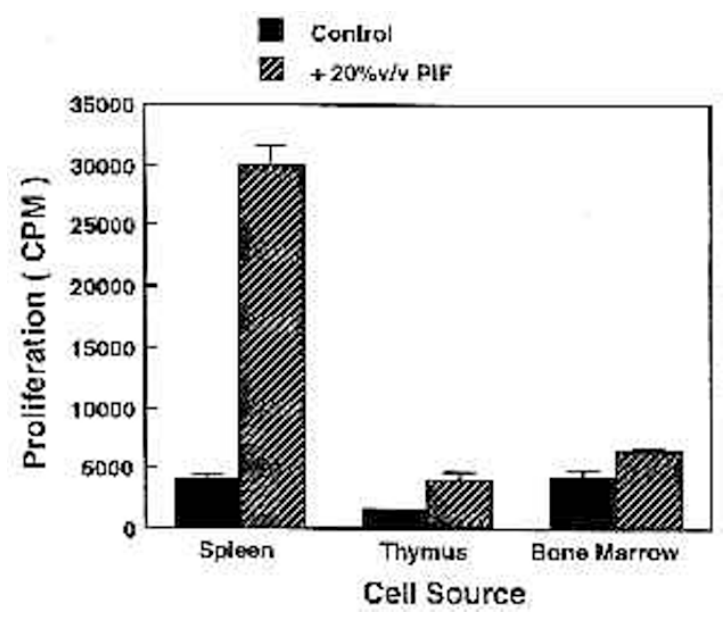

Figure 3. Proliferative response of cells derived from different lymphoid organs to PIF. Cells derived from mouse spleen, thymus and bone marrow were cultured $\left(10^{6} \mathrm{cell} / \mathrm{s} / \mathrm{ml}\right.$ in complete medium) with or without PIF ( $20 \% \mathrm{v} / \mathrm{v})$. Proliferative activity was assayed 48 $\mathrm{h}$ after initiation of culture as described in "Materials and Methods". Each point on the curve represents a mean of 3 replicate assay wells. 
that PIF may be a heat stable molecule.

\section{Effects of proteolytic enzyme treatment on PIF activity}

PIF was treated with trypsin or chymotrypsin coupled to Sepharose $\mathrm{CL}-4 \mathrm{~B}$ beads, at $37^{\circ} \mathrm{C}$ for $2 \mathrm{~h}$. After incubation, beads were removed by centrifugation and the PIF examined for biological activity. Results in Table 2 show that PIF activity was not destroyed by trypsin or chymotrypsin treatment. Enzyme-treated PIF preparation appeared to induce a better proliferative response as compared to untreated PIF preparation. Trypsin and chymotrypsin coupled to beads could efficiently degrade bovine serum albumin, indicating that the coupled enzymes were bio-logically active (results not shown).

\section{Molecular Weight of PIF}

In order to determine the molecular weight of PIF, MLC supernatant concentrated by ammonium sulfate precipitation was fractionated on a PP200SW HPLC sizing column, and column fractions were assayed for PIF activity. Results in Figure 4 show the elution profile of PIF. The column was calibrated for molecular weight determination by using BSA $\left(M_{r} 67,000\right)$, ovalbumin $\left(M_{r}\right.$ $43,000)$ and chymotrypsin $\left(M_{r} 25,000\right)$ as marker proteins. The molecular weight of PIF appears to be approximately $25 \mathrm{kDa}$.

\section{Cell population proliferating in response to PIF}

To identify the cell population proliferating in response to PIF, mouse spleen cells were subjected to anti-Thy-1 + complement treatment, or passed through nylon wool columns, or depleted of B cells by panning techniques. Mouse spleen cells treated with anti-Thy-1 + complement, lost the Con-A induced proliferative response but responded well to PIF (Figure $5 A$ ). This indicates that $T$ cells do not proliferate in response to PIF. Spleen cells passed through a nylon wool column responded poorly to PIF (Figure 5B), while spleen cells depleted of $B$ cells by panning, did not respond to PIF or LPS (Figure 5C). These results, indicate that PIF induced proliferation of B cells.

Lipopolysaccharide (LPS) is a known B cell mitogen (Anderson et al., 1973; Kearney and Lawton, 1975). The possibility of LPS contamination of PIF was examined. Polymyxin-B is a known inhibitor of the mitogenic effect of LPS (Anderson et al., 1973). The effects of polymyxin$B$ on LPS and PIF induced proliferative activity in mouse spleen cells were examined. Results in Figure 6 show that LPS induced proliferative activity was inhibited by poly-myxin-B in a dose dependent manner, but PIF induced proliferation was not significantly influenced, while poly-myxin-B by itself had no effect on spleen cell proliferation. PIF induced B cell proliferation is therefore unlikely to be due to LPS contamination of the preparation.

\section{Discussion}

Activated cells of the immune system release a large number of cytokines which in general have a plieotropic

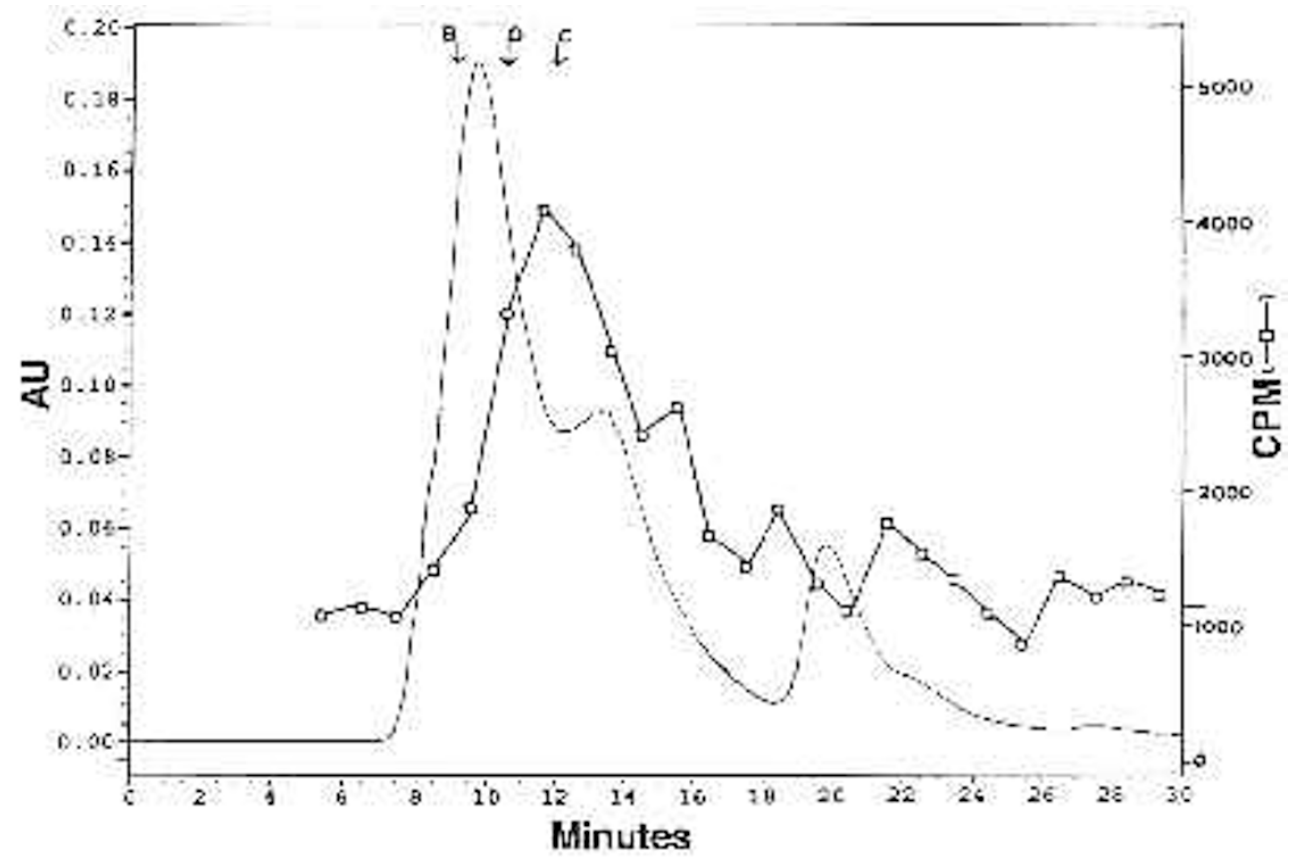

Figure 4. The elution profile of PIF on a PP200SW sizing HPLC column. Three hundred $\mu \mathrm{l}$ of PIF preparation $(900 \mu \mathrm{g}$ protein) obtained after ammonium sulfate precipitation and a $\mathrm{pH} 2.0$ dialysis of MLC supernatant were fractionated on a PP200SW HPLC column and the fractions were examined for PIF activity $(25 \%$, $\mathrm{v} / \mathrm{v})$ on mouse spleen cells as described in 'Materials and Methods'. The column was calibrated for molecular weight by using BSA (B), ovalbumin (O) and Chymotrypsinogen (C). The elution positions of each marker are designated by arrows. 

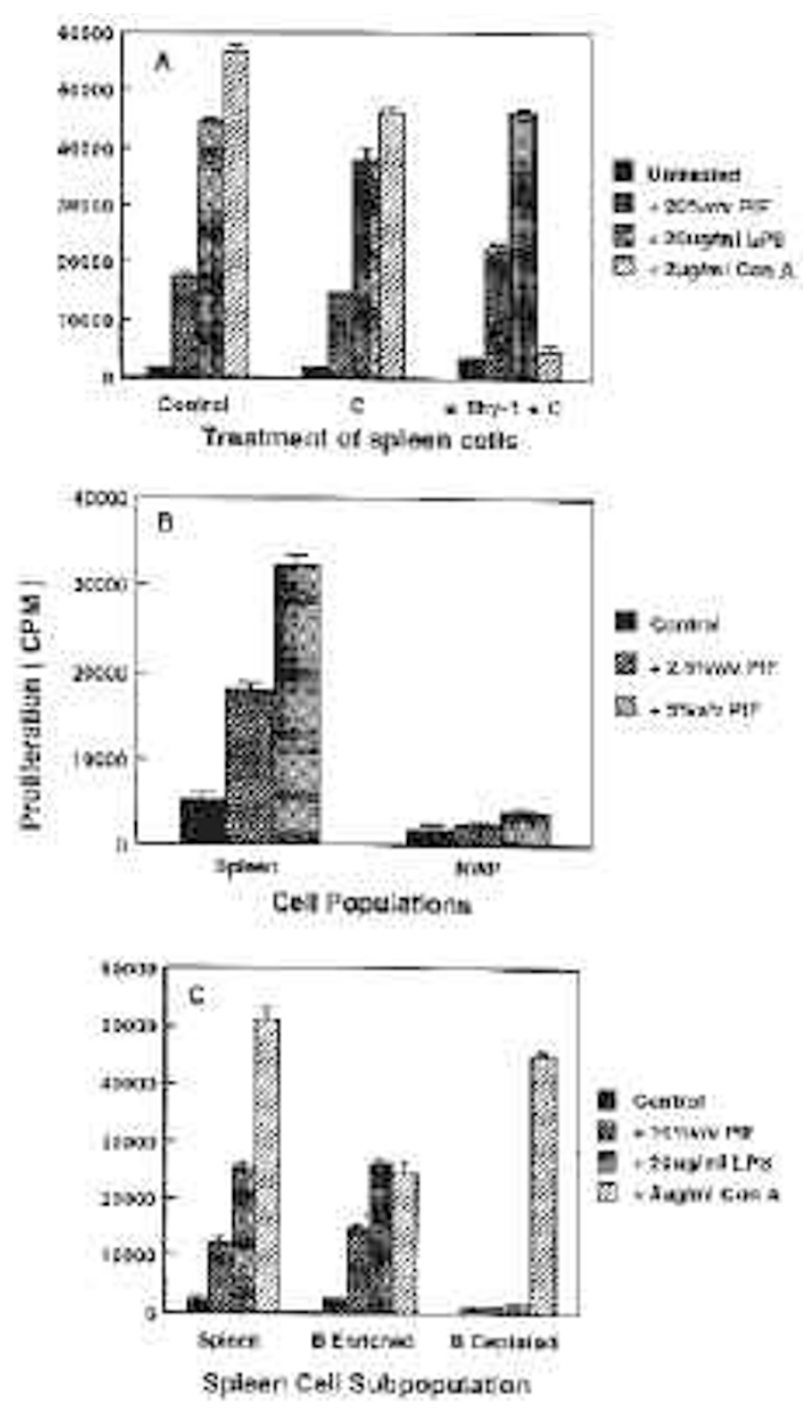

Figure 5. Proliferative activity of T cell depleted, nylon wool passaged or B cell enriched mouse spleen cell populations. Spleen cells were treated with anti Thy-1 antibody followed by complement treatment, to deplete T cells (panel A). B cells and macrophages were depleted from mouse spleen cells by nylon wool column passage (panel B). B cell enriched and depleted populations were obtained from mouse spleen cells by panning for $B$ cells (panel C). Different cell populations $\left(10^{6} \mathrm{cells} / \mathrm{ml}\right.$ ) were cultured with or without any treatment or with PIF, LPS or Con-A. Proliferative responses of different cell polulations were assessed by an $18 \mathrm{~h}\left[{ }^{3} \mathrm{H}\right]$ thymidine pulse. Each point represents a mean \pm SEM value obtained from 3 replicate assay wells.

effect on a variety of target cells. These cytokines play a crucial role in generation and regulation of an immune response. We had previously described a novel factor released by mitogen-activated spleen cells, which augmented the MHC class I antigen expression on tumor cells (Saxena et al., 1993, 1996; Puri and Saxena, 1998). Partially purified preparations of this $\mathrm{MHC}$ I augmenting factor (MHC-AF) were found to induce proliferation in

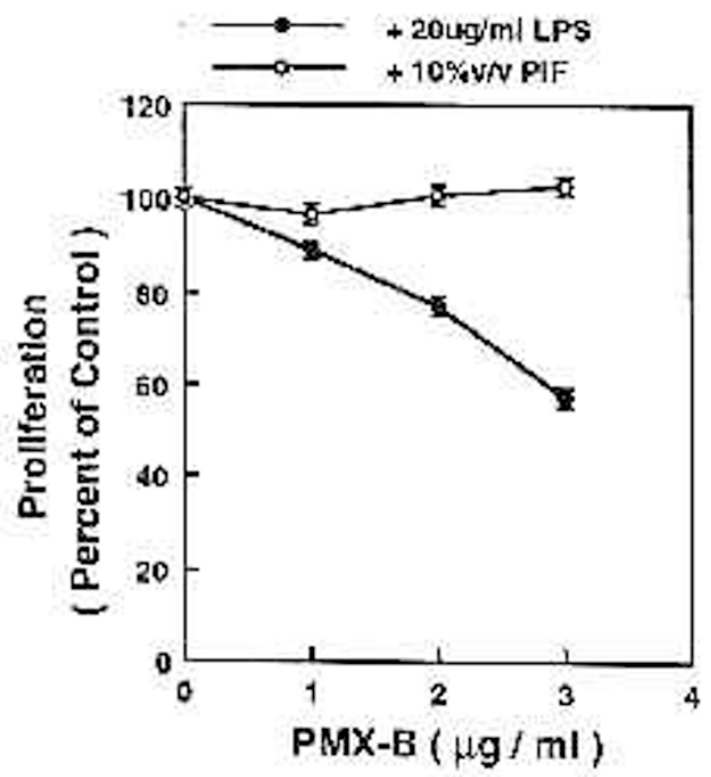

Figure 6. Effect of polymyxin-B sulphate (PMX-B) on the proliferative response of spleen cells to PIF and LPS. Mouse spleen cells were cultured with different concentrations of PMX-B, and PMX-B in the presence of LPS or PIF. Proliferative activity was assayed 48 hours after initiation of the culture as described in 'Materials and Methods'. Proliferation is expressed as a percentage of the control proliferation activity in the presence of LPS (O) or PIF (O). Each point represents a mean \pm SD value obtained from three replicate assay wells.

fresh mouse spleen cells. The factor responsible for this proliferation inducing activity (proliferation inducing factor or PIF) was clearly distinct from MHC-AF and most other known cytokines, since it was neither deactivated by heating, nor was it destroyed by proteolytic enzymes. Since PIF is potentially a novel activity, we have attempted to study its properties. A crucial issue was, the nature of the cells in mouse spleen that proliferate in response to PIF. Kinetics of response to PIF (peak on day 2) indicates that this is not similar to an antigen driven proliferation which normally peaks on day 4 to 5 . Depletion of $T$ cells by anti-Thy- $1+$ complement treatment had no effect on the induction of proliferation by PIF. In these experiments, we had an internal control of Con-A responsiveness which ensured that $T$ cell depletion had been complete. Depletion of B cells by panning on the other hand, totally blocked the effect of PIF. A B cell depleted spleen cell population, however, responded well to Con-A but not to LPS. Taken together, these results clearly indicate that PIF induced $B$ cell proliferation in mouse spleen.

LPS, a known B cell mitogen, is a bacterial product which can contaminate water or reagents. While we used only fresh reagents, the possibility of LPS contamination was considered. Polymyxin-B is a known inhibitor of the mitogenic effect of LPS (Jacobs and Morrison,1975). LPS- 
induced proliferative activity was inhibited by polymyxin$B$ in a dose dependent manner, but PIF-induced proliferation was not significantly influenced. PIF induced B cell proliferation is therefore unlikely to be due to LPS contamination of the preparation.

Some other cytokines are known to induce proliferation of cells in the B cell lineage. IL-1 promotes growth and differentiation of very early multipotential bone marrow progenitor cells (Dinarello, 1985), whereas PIF has no effect on the proliferation of bone marrow cells. IL-4 induces IgM-stimulated B cells to enter S-phase (Rotham et al., 1988) and IL-5 induces proliferation in murine B cells, costimulated with dextran sulfate (Herron et al., 1988). PIF-induced proliferation of $B$ cells does not require any costimulation. IL-7 stimulates proliferation of thymocytes and mature $T$ lymphocytes (Chantry et al., 1989) besides $B$ cells, but the effect of PIF is restricted to $B$ cells only. IL-10 induces growth and differentiation of activated human $B$ cells, whereas PIF induces proliferation of naive B cells. Biological properties of PIF thus appear to be different from those of several other known modulators of B cells. This inference is further supported by molecular characterization studies which indicate that PIF is resistant to heat treatment. Heating up to $90^{\circ} \mathrm{C}$ for 45 min did not have any effect on the activity of PIF. Also PIF activity was not destroyed by trypsin or chymotrypsin treatment. These results need not necessarily mean that PIF is not a protein molecule, though this possibility cannot be ruled out at present. There are proteins known, which are not deactivated by heating and a polypeptide lacking basic and aromatic amino acid residues may be resistant to deactivation by trypsin and chymotrypsin. Another possibility is that the biologically active protein of PIF is resistant to proteolytic enzymes.

A factor which stimulates resting $B$ cells may be of interest because such a factor may have an adjuvant effect on B cell immunity. Further work is currently underway to isolate PIF and to understand its biological role.

\section{Acknowledgement}

This project was supported by a CSIR grant to RKS. NP received a UGC fellowship.

\section{References}

Anderson, J., Melchers, F., Galanos, C. and Luderitz, O. (1973) The mitogenic effect of LPS on bone marrow derived mouse lymphocytes. J. Exp. Med. 137: 943-953

Chantry, D., Turner, M. and Feldmann, N. (1989) Interleukin-7 (murine pre-B cell growth factor/lymphopoietin 1) stimulates thymocyte growth: regulation by transforming growth factor beta. Eur. J. Immunol. 19: 783-786

Dinarello, C. A. (1985) An update of interleukin 1, from molecular biology to clinical relevance. J. Clin. Immunol. 5: 287-297

Herron, L. R., Coffmann, R. L., Bond, M.W. and Kotzin, B. L. (1988) Increased autoantibody production by NZB/NZW B cells in response to interleukin-5. J. Immunol. 141: $842-848$

Jacobs, D. M. and Morrison, D. C. (1975) Dissociation between mitogenecity and immunogenecity of TNP-Lipopolysaccharide, a T independent antigen. J. Exp. Med. 141: $1453-1458$

Julius, M. H., Simpson, E. and Herzenberg, L. A. (1973) A rapid method for the isolation of thymus derived murine lymphocytes. Eur. J. Immunol. 3: 645-649

Kearney, J. F. and Lawton, A. R. (1975) B lymphocyte differentiation induced by Lipopolysaccharide. I Generation of cells synthesizing four major Immunoglobulin classes. J.Immunol. 115: 671-676

Puri, N. and Saxena, R. K. (1998) Partial purification and characterization of a novel murine factor that augments the expression of class I MHC antigens on tumor cells. Expt. Mol. Med. (in press)

Rothman, P., Lutzker, S.; Cook, W., Coffman, R. and Alt, F. (1988) Mitogen plus interleikin4 induction of Ce transcripts in B lymphoid cells. J. Exp. Med. 168: 2385-2389

Saxena, R. K. and Adler, W. H. (1979) Modulation of natural cytotoxicity by alloantibodies I alloantisera enhancement of cytotoxicity of mouse spleen cells toward a human myeloid cell line. J. Immunol. 123: 846-851

Saxena, R. K.; Saxena, Q. B.; Sarin, A. and Herberman, R. B. (1993) in: NK cell mediated cytotoxicity: receptors, signalling and mechanisms (Lotzovz, E. and Herberman, R.B., eds.), pp. 381-392, CRC Press

Saxena, R. K., Saxena, Q. B., Whiteside, T. L., Goldfarb, R. H. and Herberman, R. B. (1996) Partial purification and characterization of a novel human factor that augments the expression of class I MHC antigens on tumor cells. J. Biosci. 21: 13-25 